\title{
Geographical Distribution and Seasonality of the Prevalence of Leucocytozoon lovati in Japanese Rock Ptarmigans (Lagopus mutus japonicus) found in the Alpine Regions of Japan
}

\author{
Koichi MURATA ${ }^{1)}$, Asumi TAMADA ${ }^{1)}$, Yoko ICHIKAWA ${ }^{1)}$, Mio HAGIHARA ${ }^{2)}$, Yukita SATO ${ }^{1)}$, Hiroshi \\ NAKAMURA $^{3)}$, Masahiko NAKAMURA ${ }^{4)}$, Takaaki SAKANAKURA ${ }^{5)}$ and Mitsuhiko ASAKAWA ${ }^{6}$

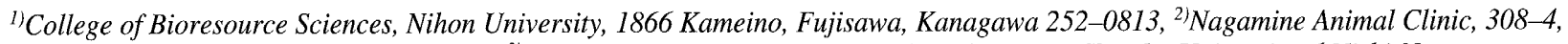 \\ Maehara, Gushikawa, Okinawa 904-2235, ${ }^{3)}$ Faculty of Education, Science and Mathematics, Shinshu University, 6 Nishi-Nagano, \\ Nagano 380-8544, ${ }^{4}$ Course of Science, Joetsu University of Education, 1 Yamayashiki, Joetsu, Niigata 943-8512, ${ }^{5}$ The Institute for \\ Alpine Environment and Biota, 5089 Hakuba, Kitaazumi-gun, Nagano 399-9301 and ${ }^{6}$ School of Veterinary Medicine, Rakuno Gakuen \\ University, 582 Midori-cho, Bunkyo-dai, Ebetsu, Hokkaido 069-8501, Japan
}

(Received 25 August 2006/Accepted 1 November 2006)

ABSTRACT. In this study, we investigated the geographical distribution and seasonality of Leucocytozoon lovati infection in the Japanese rock ptarmigan (Lagopus mutus japonicus); this bird is one of the special natural monuments of Japan that inhabits the Japanese alpine regions. We examined blood samples from birds captured in the Kubiki, Hida, and Akaishi mountain ranges for three years from 2002 to 2005. Seventy-three blood samples from 42 males, 19 females, and 12 birds of unknown sex were used for this study. The rate of infection with $L$. lovati was $78.1 \%$ in the 73 birds examined. We demonstrated that the $L$. lovati infection was distributed across wide ranges of ptarmigan populations from the northern to the southern alpine zones. There was no sex bias in the prevalence ratio. The prevalence of $L$. lovati and the level of parasitization of the blood cells tended to increase from spring through summer; in contrast, a decrease was observed from summer through autumn. Although $L$. lovati infection was observed in a number of local populations inhabiting three mountainous regions, no infected birds were found in Mt. Johnen-dake and Mt. Maejohnen-dake. It is necessary to continue surveying the relationship between the population dynamics of the ptarmigan and the density of the arthropod vector from the perspective of in situ conservation of this endangered species.

KEY WORDS: geographical distribution, hematozoa, Japanese rock ptarmigan, Leucocytozoon lovati, vulnerable species.

J. Vet. Med. Sci. 69(2): 171-176, 2007

The rock ptarmigan (Lagopus mutus) is a bird species belonging to the order Galliformes; it has adapted to the cold environments of the Northern Hemisphere and 23 to 30 subspecies have been recognized [5, 13]. The Japanese rock ptarmigan (L. m. japonicus), one of these subspecies, inhabits mountain ranges in Japan situated at an altitude of 2,400 $\mathrm{m}$ above sea level or higher [10].

Presently, the Japanese ptarmigan inhabits regions above the timberline in some mountainous regions isolated from each other. In recent times, the number of birds in several local populations has declined alarmingly and is presumed to be less than 3,000 [18]; however, the causes of this decline have not been elucidated yet. This decrease in the population of this bird and its habitat being restricted to the alpine environment led to the species being designated as a special natural monument of Japan in 1955; further, it has been listed among the vulnerable species in the Japanese Red Data Book [18].

Recent studies have found that Japanese rock ptarmigans are infected with Leucocytozoon lovati [10]. Infection with these hematozoan parasites is reported to be prevalent in wild ptarmigans and grouses in the Palearctic and Nearctic regions [3], and the infection in the Japanese rock ptarmigan indicates the distribution of $L$. lovati in the lower latitudes.

L. lovati is thought to be transmitted by the black fly (Simulium spp.) [8], and infected birds generally show inapparent infection [7]. However, Clark (1935) reported fatal cases in chicks of the ruffed grouse (Bonasa umbellus) [4]. The survival rate among chicks of the Japanese rock ptarmigan is low and it might drop to $10 \%$ or lower (T. Sakanakura unpubl. data); therefore, a relation between the $L$. lovati infection and the decrease in the population of the ptarmigans is suspected [10]. Environmental deterioration and/or climate changes because of global warming in the alpine zones, which are the unique habitats of the rock ptarmigan, is generally suspected to be the main cause of the declining population of the species. On the other hand, few studies have investigated the influence of etiologic agents on the population of the species $[10,12,14]$. Therefore, we surveyed the geographical distribution and seasonality of the prevalence of $L$. lovati in wild Japanese rock ptarmigans in order to identify and analyze the causes of the decrease in their population. This study aimed at accumulating veterinary medical information on this endangered bird species and contributing to its in situ conservation in Japan.

\section{MATERIALS AND METHODS}

Number of birds surveyed: For this study, we collected blood samples from wild ptarmigans for approximately three years from April 2002 to June 2005. These samples were collected from 16 mountainous regions in the Japanese Alps spanning across the Kubiki, Hida (northern Japanese Alps), and Akaishi (southern Japanese Alps) mountain 


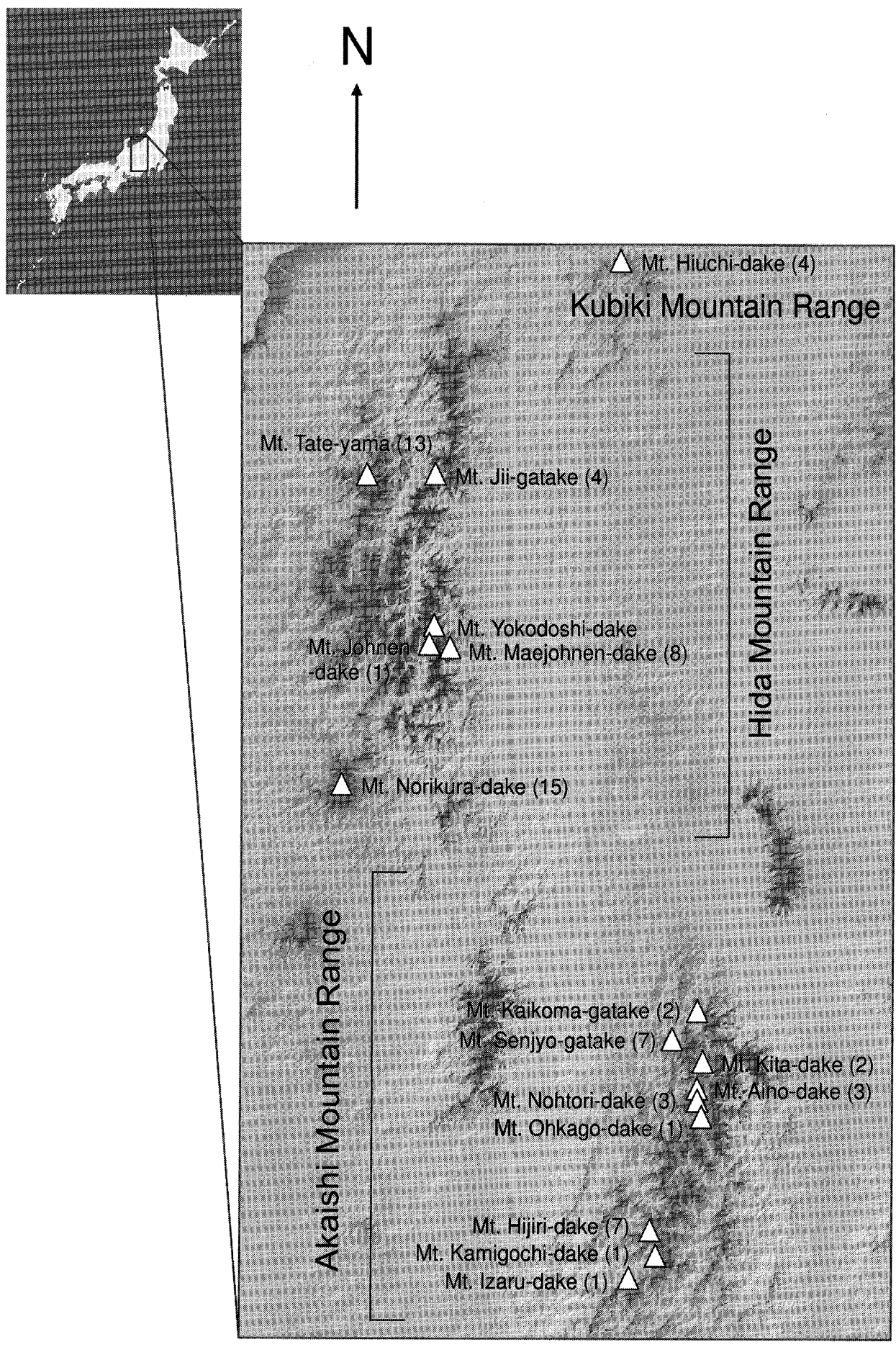

Fig. 1. Sixteen mountainous areas belonging to the Kubiki, Hida, and Akaishi mountain ranges, where the birds were captured to study the Leucocytozoon lovati infection in Japanese rock ptarmigans (Lagopus mutus japonicus). The map was made by the freeware soft for 3D landscape navigator (KASHMIR-3D version 8.6.9; http://www.kashmir3d.com/index-e.html) with the digital maps from The Geographical Survey Institute of Japan.

ranges (Fig. 1) during the population surveys by ornithologists. The birds were captured humanely by using a wire noose with the permission of the Ministry of the Environment, Government of Japan.
The total number of birds captured was 86 (male, 51; female, 23; and sex unknown, 12) and they were all sexually matured (1-year-old or more). All birds were recognized individually with their leg bands. The details of the number 
of birds captured in each districts are as follows: Kubiki mountain range, 4 (all sex unknown); Hida mountain range, 35 (male, 23 and female, 12); and Akaishi mountain range, 47 (male, 28; female, 11; and sex unknown, 8).

Blood sampling and blood films: Blood was collected from the wing vein of the birds, and heparin-Na was used as an anticoagulant. Most of the blood films were prepared and fixed with $99.5 \%$ methanol at the site of collection. Some of the blood samples and blood films without methanol fixation were collected and prepared by field researchers on our request and transported to our laboratory.

Blood samples that had been transported to the laboratory in cold storage within a plastic container were also used for preparing blood films in the above mentioned manner. The blood films were fixed with methanol and stained with Giemsa solution (pH 7.2) and/or Hemacolor ${ }^{\mathrm{TM}}$ (Merck Ltd., Shimomeguro 1-chome, Meguro-ku, Tokyo, Japan).

Among the blood films prepared from 86 birds, 13 films were unsuitable for microscopic observation and were excluded. Eventually, 73 blood films from 42 males, 19 females, and 12 birds of unknown sex were used for this study.

Morphological observation: Blood films were observed under an optical microscope $(\times 100-\times 1,000)$. Approximately 100 fields were observed under a magnification of $x$ 100 , which indicates that we examined approximately 400,000 blood cells for the presence of infected cells. We observed the infected cells and the morphological characteristics of the gametes minutely with oil immersion objectives under a magnification of $\times 400$ and $\times 1,000$.

Calculation of the infection rate: For evaluating the parasitemia, we used the Ashford Scale [2,10]. This scale is described as follows: grade 0 , no infected cells are observed in any of the fields under $\times 100$ magnification; grade 1 , less than one infected cell is observed in 100 fields under $\times 400$ magnification; grade 2, 1-10 infected cells are observed in 100 fields under $\times 400$ magnification; grade $3,11-100$ infected cells are observed in 100 fields under $\times 400$ magnification; grade 4, more than 100 infected cells are observed in 100 fields under $\times 400$ magnification. The rate of parasitized cells, which indicates the number of infected blood cells against the total number of blood cells, was also calculated after observing 5,000 blood cells. All results were presented as mean \pm standard deviation with their ranges in parentheses.

Geographical distribution of infection: The number of infected and uninfected birds in 16 mountainous areas belonging to the Kubiki, Hida, and Akaishi mountain ranges was examined (Fig. 1). For comparison of infection rate by Ashford Scale among three mountain ranges, analysis of variance (ANOVA) was used. Upon detection of significant increases by ANOVA, post-hoc pairwise comparisons were conducted using Tukey-Kramer's HSD test, with the level of statistical significance taken as $P<0.05$.

Seasonality of infection: The variation in the infection rate of $L$. lovati across three seasons from spring to autumn was compared among all the samples from the three moun- tain ranges by the Ashford Scale. The three seasons were defined as follows: spring, March to May; summer, June to August; and autumn, September to November. Samples could not be collected in winter because of the severe climatic conditions in the high mountainous regions. We collected blood samples from 73 birds in all the seasons; 15 in spring, 35 in summer, and 23 in autumn. For comparison of three seasons, we used the same statistical analysis as for the geographical distribution of infection.

Sex difference between the infected and uninfected birds: The sex difference in the infection rates was calculated by examining 61 specimens comprising 42 males and 19 females. The presence of sex differences was examined statistically by using the Yates' continuity correction chisquare test for independence.

\section{RESULTS}

Morphological observation: On Giemsa staining, the cytoplasm of the macrogametocyte was observed to be dark violet-blue; further, we observed a vacuole and deep purple granules. The nucleus acquired a bright red-violet color. The nucleus of the host cell was pushed onto the edge of the cell wall and was observed to be deep red-purple and elongated. The cytoplasm and the nucleus of the microgametocyte were observed to be pale blue and blue-violet, respectively.

We observed that the cytoplasm of both macrogametocytes and microgametocytes of the infected host cell was distorted and acquired a fusiform shape (Fig. 2). On the basis of the morphological characteristics described above, the parasite was identified to be $L$. lovati $[9,10]$.

Representative stained blood films from infected birds have been deposited in the Meguro Parasitological Museum (4-1-1 Shimomeguro, Meguro, Tokyo 153-006, Japan; accession numbers MPMCol. 18818-18819).

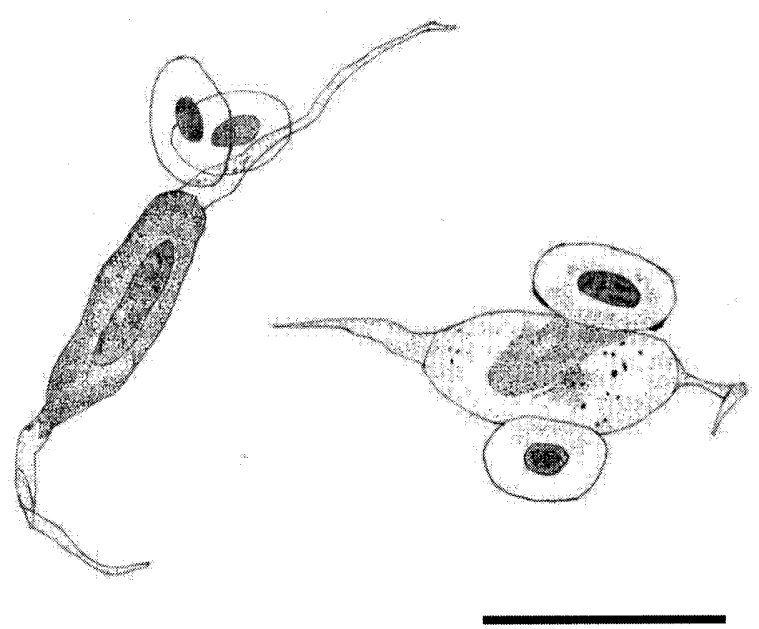

Fig. 2. Schema of Leucocytozoon lovati detected in Japanese rock ptarmigan. The host cell infected with the macrogameocytes (left) and the microgametocytes (right) was elongated at the both ends and distorted into a fusiform shape. Bar $=10 \mu \mathrm{m}$. 


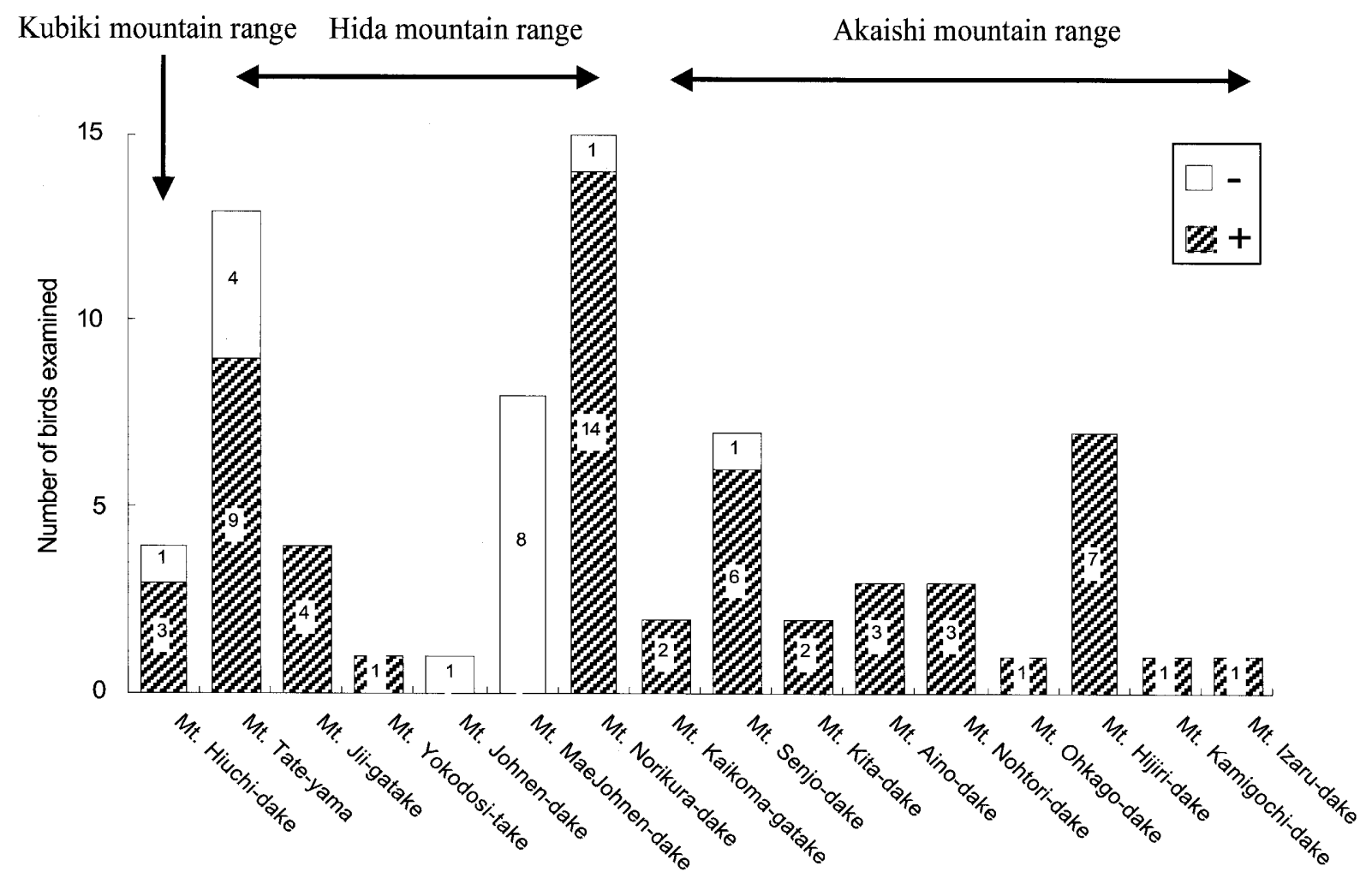

Fig. 3. Prevalence of Leucocytozoon lovati in each of the 16 mountainous areas consisting of three mountain ranges. The number shown within each bar indicates the one of infected/uninfected birds examined in that area. The shaded bar shows the number of infected birds and the white bar shows the uninfected birds. Altogether, the positive rate in 73 birds among the three mountain ranges was $78.1 \%$. Individually, the positive rate was $75.0 \%$ of 4 in the Kubiki, $66.7 \%$ of 35 in the Hida, and $96.3 \%$ of 47 in the Akaishi mountain ranges, respectively.

Infection rate and geographical distribution of infection: The percentage of birds belonging to each grade on the Ashford Scale is as follows: grade $0,22 \%(16 / 73)$; grade 1 , $20.5 \%$ (15/73); grade $2,34.2 \%$ (25/73); grade $3,23.3 \%$ (17/ $73)$; and grade $4,0 \%$. The parasitized rate in blood cells among the 73 birds from the three mountain ranges was 0.02 $\pm 0.019 \%(0-0.1 \%)$. The infection rate observed in the samples from each mountain range was as follows: $0.013 \pm$ $0.01 \%(0-0.02 \%)$ in 4 birds from Kubiki, $0.015 \pm 0.012 \%$ $(0-0.04 \%)$ in 42 birds from Hida, and $0.036 \pm 0.027 \%(0$ $0.1 \%$ ) in 27 birds from Akaishi.

The overall rate of infection with $L$. lovati as observed in 73 birds was $78.1 \%$. On comparing the prevalence of the hematozoa in the 16 areas belonging to the three mountain ranges, we found that the birds in the Akaishi mountain range showed the highest infection rates $(96.3 \%)$, followed by those in the Kubiki mountain range $(75.0 \%)$ and those in the Hida mountain range $(66.7 \%$ ) (Fig. 3). The difference in the prevalence of this infection as scored on the Ashford Scale was slightly significant among the three ranges $\left(\chi^{2}=\right.$ $6.43, P=0.04)$; further, this difference was also significant between the Hida and the Akaishi mountain ranges $\left(\chi^{2}=\right.$ $6.44, P=0.011)$. No infected birds were found in the habitats around Mt. Johnen-dake and Mt. Maejohnen-dake of the Hida mountain range.
Seasonality of infection: We compared the grades of parasitemia observed in the birds in the three seasons that were obtained by using the Ashford Scale. Birds that had infections corresponding to grades 1 and 2 accounted for $33.3 \%$ of the 15 birds examined in spring; the birds that had infections corresponding to grades 2 and 3 , which signifies comparatively high parasitemia, accounted for $40 \%$ of those examined in summer. In autumn, $91.3 \%$ of the 23 birds examined were observed to be infected; this value was higher than that observed in summer $(88.6 \%$ of the 35 birds). However, $47.6 \%$ of the 21 infected birds had infections of grade 1, which signifies low parasitemia. The number of birds with infections of grade 3 increased from spring to summer and decreased thereafter to autumn; that of birds with infections of grade 2 increased from spring to summer and autumn (Fig. 4). The variations in the infection rate as graded by the Ashford Scale across the three seasons were statistically significant $\left(\chi^{2}=27.32, P<0.001\right)$.

Difference in the infection rate among the sexes: The prevalence of the L. lovati infection was $76 \%$ in males and $74 \%$ in females. No statistically significant differences were observed between the male and female birds $\left(\chi^{2}=\right.$ $0.012, P=0.912$ ). Since the difference in the prevalence of the infection in both sexes was not significant, individuals of both sexes were included in the analysis for the geographi- 


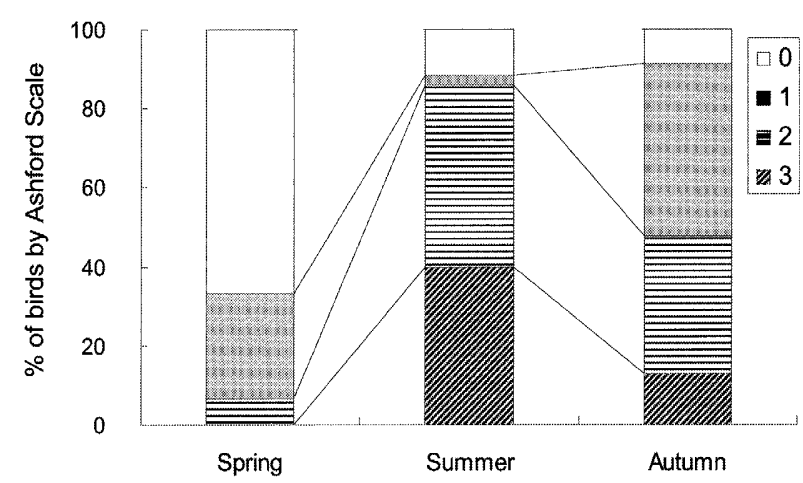

Fig. 4. The parasitemia level of Loucocytozoon lovati in 73 birds from the three mountain ranges using the Ashford Scale [2] was demonstrated in the three seasons, from spring to autumn. The numbers from 0 to 3 in the explanatory note and the four patterns of the bar corresponding to each number indicates the grades of the Ashford Scale. Blood samples were collected from 15 birds in spring, 35 birds in summer, and 23 birds in autumn from the three mountain ranges.

cal distribution and the seasonality of the infection caused by the parasite.

\section{DISCUSSION}

L. lovati infection was observed in $87.5 \%$ of the 16 areas surveyed across the three mountain ranges, with the exception of Mt. Johnen-dake and Mt. Maejohnen-dake. Infection of the ptarmigan and the grouse with this parasite was observed across a wide-range of their habitat in both Nearctic and Palearctic regions $[6,11]$. In our study, we clarified that these hematozoa were distributed widely throughout the northern and southern populations of the ptarmigan in the Japanese Alps (Fig. 3). With regard to the prevalence of the parasite and the level of parasitized blood cells in the species in each mountain region, the highest infection rate $(96.3 \%)$ and the rate of parasitization of cells $(0.036 \pm 0.027 \%)$ were observed in the population from the Akaishi mountain range. The comparatively high prevalence observed in this region might be attributed to the higher population density and longer active period of the arthropod vector at lower latitudes. It will be required to collect more blood samples from birds in each mountain region for a comparative study to determine whether the high infectious rate is caused by regional characteristics or the sampling season. Antibody detection for $L$. lovati infection should be also considered to understand the infectious status more precisely near future.

No infected birds were observed among the population in Mt. Johnen-dake and Mt. Maejohnen-dake in the Hida mountain range. The absence of infected birds in these areas, where ptarmigans exhibit comparatively stable population dynamics (H. Nakamura unpubl. data), were suspected to result from the absence of the arthropod vector of L. lovati in these areas, absence of infected birds overall, or undetectably low parasitemia. Since infected birds were found in the population on Mt. Yokodoshi-dake, which is proximal to Mt. Johnen-dake and Mt. Maejohnen-dake, it could be inferred that the ptarmigans and the vector of $L$. lovati are isolated from the neighboring regions where the infected birds exist. As there is concern about the spread of L. lovati infection from the infected area, future studies should include the monitoring and surveillance of the population on Mt. Johnen-dake and Mt. Maejohnen-dake.

The level of parasitemia in the 73 birds examined increased significantly from spring to summer; in contrast, the parasitemia level decreased from summer to autumn (Fig. 4). A sharp increase in the prevalence of L. lovati in June has been observed in the willow ptarmigan ( L. lagopus) from northwestern British Columbia [15]. It is assumed that the level of parasitemia is associated with the population density of the arthropod vector, which is surmised to belong to the Simulium spp. and whose breeding season is the beginning of summer [15]. Therefore, control measures against this vector in summer will be required if $L$. lovati causes damage to small populations of the rock ptarmigan in its isolated habitats in Japan.

There are many reports regarding the sex bias in parasiteinfected animal hosts [16]. Body size, reproductive behavior of hosts, and other factors are indicated as reasons for the sex bias [1]. A report by Mahrt (1981) showed that there was no significant difference in the rate of infection with hematozoa between the yearlings and adults of the willow ptarmigan; the report, thus, supports this notion [15].

This study clarified that there is a geographical distribution and seasonality in the prevalence of L. lovati in the Japanese rock ptarmigan. The detailed dynamics of $L$. lovati infection in the ptarmigan population in each area could be better understood by collecting more blood samples from the birds every year. However, follow-up surveys on $L$. lovati infections, which require frequent capturing of the birds, are not simple because the Act for the Conservation of Endangered Species of Wild Fauna and Flora strictly prohibits the capture of the Japanese rock ptarmigan. Therefore, in order to perform a diachronic study to understand the effects of geographical distribution and seasonality of $L$. lovati infection in this species, it will be practical to detect the parasite gene from the arthropod vectors and study the epidemiology of the infection indirectly by using molecular techniques. The risk assessment of the L. lovati infection in the Japanese rock ptarmigan could be carried out by studying the relationship between the population density and the prevalence of infection with $L$. lovati, which is transmitted by the arthropod vector. It is necessary to explore practical methods to study L. lovati infections in detail for the conservation of this vulnerable species.

ACKNOWLEDGMENTS. We thank Organization of the Ministry of the Environment and the staff of Shinshu University and Joetsu University of Education for their kind support to the study. We are also grateful to the members of Toyama Rock Ptarmigan Research Group and Mr. Tsutomu Murayama of Yamanashi Prefecture for the cooperating of the blood sampling. Koichi Murata and Yukita Sato were 
supported by the Grants from Life Science Center of Nihon University, and Koichi Murata, Yukita Sato, Masahiko Nakamura and Mitsuhiko Asakawa were supported by the Grants-in-Aid for Scientific Research (No. 16510179) from Ministry of Education, Culture, Sports, Science and Technology.

\section{REFERENCES}

1. Arneberg, P., Skorping, A. and Read, A.F. 1998. Parasite abundance, body size, life histories and the energetic equivalence rule. Am. Nat. 151: 497-513.

2. Ashford, R.W., Wyllie, I. and Newton, I. 1990. Leucocytozoon toddi in British sparrowhawks Accipiter nisus: observations on the dynamics of infection. J. Nat. Hist. 24: 1101-1107.

3. Bennett, G.F., Earle, R.A., Peirce, M.A., Huchzermeyer, F.W. and Squires-Parsons, D. 1991. Avian leucocytozoidae: the leucocytozoids of the phasianidae sensu lato. J. Nat. Hist. 25: 1407-1428.

4. Clark, C.H.D. 1935. Blood parasites of ruffed grouse (Bonasa umbellus) and spruce grouse (Canachites canadensis), with description of Leucocytozoon bonasae n. sp. Can. J. Res. 12: 646-650.

5. del Hoyo, J., Elliott, A. and Sargatal, J. 1994. pp. 638. Handbook of the Birds of the World (Volume 2): New World Vultures to Guineafowl. Lynx Edicions, Barcelona.

6. Dunbar, M.R., Torquist, S. and Giordano, M. R. 2003. Blood parasites in sage-grouse from Nevada and Oregon. J. Wildl. Dis. 39: 203-208.

7. Fallis, A.M. and Bennet, G.F. 1958. Transmission of Leucocytozoon bonasae Clarke to ruffed grouse (Bonasa umbellus L.) by the blackflies Simulium latipes $\mathrm{Mg}$. and Simulium aureum Fries. Can. J. Zool. 36: 533-539.

8. Fallis, A.M. and Bennet, G.F. 1961. Sporogony of Leucocyto- zoon and ceratopogonids and revised classification of the Haemosporidiida. Can. J. Zool. 39: 215-228.

9. Fantham,H.B. 1910. Observation on the parasitic protozoa of the red grouse (Lagopus scoticus), with a note on the grouse fly. pp. 692-709. In: Proceedings of the General Meetings for Scientific Business of the Zoological Society of London.

10. Hagihara, M., Yamaguchi, T., Kitahara, M., Hirai, K. and Murata, K. 2004. Leucocytozoon lovati infections in wild rock ptarmigan (Lagopus mutus) in Japan. J. Wildl. Dis. 40: 804807.

11. Holmstad, P.R., Anwar, A., Iezhova, T. and Skorping, A. 2003. Standard sampling techniques underestimate prevalence of avian hematozoa in willow ptarmigan (Lagopus lagopus). $J$. Wildl. Dis. 39: 354-358.

12. Ishihara, S., Shiibashi, T. Sato, Y., Murata, K. and Nogami, S. 2006. Two Eimeria Species Isolated from Wild Japanese Rock Ptarmigans (Lagopus mutus japonicus) in Japan. J. Vet. Med. 68: $991-993$.

13. Johnsgard, P.A. 1983. p. 413. The Grouse of the World. The University of Nebraska Press, U.S.A.

14. Kamimura, K. and Kodama, H. 1981. Eimeria uekii sp. n. from Lagopus mutus japonicus (Clark) in Mt. Tateyama, the Japan Alps. Jpn. J. Parasitol. 30: 467-470.

15. Mahrt, J. L. 1981. Seasonal prevalence of hematozoa in willow ptarmigan (Lagopus lagopus) from northwestern British Columbia. J. Parasitol. 67: 277-278.

16. Poulin, R. 1996. Sexual inequalities in helminth infections: a cost of being male? Am. Nat. 147: 287-295.

17. Valkiunas, G. 2005. p. 932. Avian Malaria Parasites and Other Haemosporidia. CRC Press, Florida.

18. Wildlife Division of the Ministry of the Environment. 2002. $\mathrm{p}$ 278. Red Data Book: Birds, Ministry of the Environment of Japan, Tokyo. 